\title{
1999 Presidential Address to the National Society of Genetic Counselors
}

\author{
Wendy R. Uhlmann ${ }^{1,2}$
}

It is a tremendous honor to be standing here today as president of the National Society of Genetic Counselors (NSGC), and I want to express my appreciation for this opportunity. As I look to the year ahead and the different responsibilities of this position, I admit to having feelings of both excitement and some trepidation. It is a daunting task to lead an organization, especially into the next century, and at a time when the whole field of genetics is rapidly advancing. While I anticipate less sleep and more chocolate consumption in the year ahead, I am firmly committed to doing my best to represent and lead NSGC. I would like to share some thoughts about our annual education conferences and the recent board decision, the importance of our participation in the wider genetics community, and to present some projects for the coming year.

The first NSGC Annual Education Conference that I attended was in 1987 in San Diego. I was then a student in the University of Michigan genetic counseling program, and my whole class was there-all two of us. I was 1 of 350 attending the conference. Since 1987, the number of conference attendees has grown to more than 800 , and NSGC membership has more than doubled to almost 1,800 . The fact is that the number of conference attendees in this room today significantly exceeds what was our total membership in 1987. Being at a conference, especially for the first time is overwhelming, and so I confess that I went off to the outdoor hot tub. I thought I was escaping, but I was mistaken. Instead, I was networking, albeit in a less formal setting! As I learned from the hot tub experience, networking is an important aspect of these conferences, and it occurs in a multitude of places.

I initially became involved in NSGC thanks to the mentoring of my program director, Diane Baker, M.S. While I have given a lot of time to NSGC over the years, I have gained much in return-increased knowledge, new skills, and

\footnotetext{
${ }^{1}$ University of Michigan Health System, Ann Arbor, MI.

${ }^{2}$ Correspondence should be directed to Wendy Uhlmann, University of Michigan Health System, Division of Medical Genetics, 4301 MSRB III, Box 0638, Ann Arbor, MI 48109-0638.
} 
enduring friendships. Some counselors may hesitate to become involved, unsure as to whether they have anything to contribute. The fact is that we all have something to contribute, whether we are new to the field or have been around since its inception.

We work in a hybrid field that brings together two distinct disciplines, genetics and counseling. Our field is not static, but rapidly evolving. As a result, it is a constant challenge to keep our fund of knowledge current. What we may have done 6 months ago for a case may be different from what we would do today. In our code of ethics, we state that genetic counselors "strive to continue their education and training" and "keep abreast of current standards of practice" (National Society of Genetic Counselors Code of Ethics, 1992). Attending NSGC meetings and conferences attended by geneticists and other medical specialists with whom we work is important for our continuing education. By attending the same conferences as our physician colleagues, we show that although our degrees are different, we are equals in seeking new knowledge and keeping ourselves updated. By presenting at these conferences, we demonstrate our expertise and increase the visibility of our profession.

The NSGC has had a long history of holding conferences at the same time as the American Society of Human Genetics (ASHG). At the NSGC Board of Directors meeting, held in March of this year, we made the decision to hold independent conferences beginning in the year 2001. We took into consideration many factors including cost, logistics, and continuing education opportunities. As our conference program has expanded, it has become increasingly difficult to schedule short courses, meeting times for special interest groups (SIGs), and gatherings for genetic counseling programs. Our conferences have become so tightly scheduled that there are breakfast lectures and meetings starting at 6:30 A.M.- the equivalent of 3:30 A.M. if you are from the West Coast and the conference is being held in an East Coast city. With more than 800 attendees, our conferences have grown to the point where fewer hotels can accommodate our membership, and we will soon need to hold our conferences at a convention center. The growth in our meeting attendance and our ability to hold independent conferences is truly a milestone for our profession.

Many of us have been able to attend the ASHG meeting because it is held back-to-back with NSGC. But if you think about it, all that is being saved is airfare. Whether the meetings are held together or separately, there are still registration fees and hotel and meal expenses. The fact that our meeting will be held at a different time from the ASHG meeting should not diminish our attendance but actually facilitate it. Few offices can afford to have genetic counselors gone for over a week. While spouses and partners may be accommodating for a 10-day absence, children are less forgiving. Our ability to take in information is diminished after several days at meetings, so it is harder to take full advantage of all that is available. It is our goal that NSGC conferences will strive to meet the continuing education units (CEU) requirements necessary for American Board of Genetic Counseling (ABGC) recertification. We hope that having our conference at a different time 
will make it possible for more of our geneticist colleagues to consider attending and presenting at NSGC conferences.

Genetic counselors have a solid track record of serving on the American Society of Human Genetics Board of Directors and ASHG committees. While genetic counselors cannot serve on the Board of Directors of the American College of Medical Genetics, genetic counselors do serve on its committees. An impressive number of genetic counselors have moderated sessions and presented papers and posters at ASHG and ACMG meetings. It is very important that we continue to be active participants in these genetics organizations. By joining committees and serving on boards, we have the opportunity to be at the table and have a voice in decisions that impact our work. Sometimes it is those chance hallway discussions that make a critical difference. It is therefore important that we be both at the table and in the hallways of these meetings so that our voices are heard.

Over the course of our professional lives, we will be spending a lot of time together - in fact, probably more time together than we will spend with friends and relatives. Assuming that the national meeting is 4 days and the regional meeting is 2 days, that's almost a week together per year. Multiply that by 30 years of working and that's more than 6 months we will spend together. For those of you who figure on working as genetic counselors 40 years plus, plan on spending more than 8 months together. How rewarding our time together is will depend on what we make of it. Therefore, it is important to be involved, communicate your ideas, and contribute what you can so that our time together is well spent.

There are many aspects of our professional lives that we take for granted today that took a lot of time and effort to achieve. One only has to listen to the reports at this business meeting or read our annual report to appreciate the many projects that NSGC members have initiated and are actively working on. I have selected a few to highlight, in addition to suggesting some new initiatives:

- Billing and reimbursement. Studies have shown that the time involved in case preparation and follow-up for a genetics patient can amount to several hours (Bernhardt et al., 1987; Bernhardt and Pyeritz, 1989; Surh et al., 1995). This time is critical for providing accurate information and quality care to our patients; however, it is not billable. Additionally, genetic counseling provided by genetic counselors is not billable. We need to continue to work with other genetics organizations to help establish a comprehensive CPT (Current Procedural Terminology) code for genetic counseling.

- Continuing growth of our executive office. NSGC has been extremely fortunate to have an exceptional executive director, Bea Leopold, M.A., and we hope she will continue in this role for many years to come. In the past 12 years, our executive office has grown from a single-person effort to include two part-time staff members and a part-time Web consultant. The services offered to our members have significantly increased, and more outsourcing has been needed. The fact that NSGC has operated out of a home office, with 
no rental fees, has been a significant savings to NSGC. However, continuing growth in services to our members must be anticipated. In addition to evaluating staffing and service issues, we need to consider whether NSGC would benefit from having a satellite office in the D.C. area, where the other major genetics organizations, $\mathrm{NIH}$, and Congress are located. I will be appointing an ad hoc committee to evaluate the administrative needs of the NSGC.

- Marketing. Our marketing efforts began almost 3 years ago with the implementation of GeneAMP. To date, 23 projects initiated by NSGC members have been funded, including the development of informational brochures about genetic counseling for health care purchasers and mailings targeting members of Congress and the media. An NSGC booth was developed and has been displayed at oncology, psychiatry, and public health meetings. Successful marketing will be important for the future of our profession. During the coming year, NSGC will be evaluating our marketing and will explore whether a marketing consultant can assist with these efforts.

- Enhanced electronic communication. The NSGC Listservs have been an effective way for members to seek input on cases, share resources, alert members to pertinent articles and upcoming conferences, and discuss different issues. Our homepage, www.nsgc.org, is a resource for students, patients, health care professionals, genetic counselors, and the general public. In addition to being a useful resource, our homepage can be an inexpensive and far-reaching way to market our profession and increase our visibility. This year, I hope we will continue efforts to expand and enhance our homepage and other forms of electronic communication.

- Development of NSGC slide sets and other educational resources. I would like to see NSGC take the lead in developing educational resources and slide sets that explain genetic counseling and genetic testing for genetic conditions, much like the one developed by ASCO (American Society of Clinical Oncologists) for cancer. As experts in the areas of genetic counseling and genetic testing, we should not pass up the opportunity to share our expertise and develop educational resources that can be used by other professionals and for the general public. I would like to see our publication efforts expanded, and I encourage the SIGs especially to develop educational resources.

- Practice guidelines. Genetic counselors work as part of a team. While different genetics organizations are working on practice guidelines, I think it would be beneficial to make sure these efforts are collaborative. It does not make for quality patient care to have geneticists and genetic counselors following different practice guidelines. These differences are better hashed out when practice guidelines are developed in the first place. We also need to consider our intended and future use of practice guidelines. Given the number of genetic conditions, it is not practical to develop practice guidelines for each condition. Instead we need to consider developing 
practice guidelines that will have wide applicability. For example, although this was not the original intention, the guidelines developed by the International Huntington Association and the World Federation of Neurology (International Huntington Association and World Federation of Neurology Research Group on Huntington's Chorea, 1994) for predictive testing for Huntington disease have also been implemented when offering testing for other neurological conditions and some hereditary cancer syndromes.

- Strengthening our links with other genetics organizations. As we move toward holding independent conferences, it is critical that we communicate to the wider genetics community our strong intent to stay involved in these genetics organizations. I will be asking NSGC committee chairs to contact their counterparts in ASHG and ACMG to facilitate communication and knowledge of each other's activities. In addition, I will continue to be in contact with ASHG and ACMG regarding issues and membership on their committees to help ensure that genetic counselors are represented. We will also explore whether there should be additional liaisons with other genetics and related organizations. Perspectives in Genetic Counseling will be initiating a new column, "Reaching Out: The Wider Genetics Community," to highlight other genetics organizations, their projects, and how counselors have become involved. I encourage NSGC members to become familiar with genetics organizations, their resources, and their position statements, which can be easily accessed through their homepages.

Genetic counseling in the year 2000 is now only 77 days, 9 hours, away (depending on your time zone). What this will encompass and what role genetic counselors will play should be considered by all of us. Certainly in the next few years we can anticipate the complete mapping of the human genome and the subsequent availability of more testing options for our patients. Less frequently will we be saying to patients, "You are at an increased risk for this condition; however, there is no genetic testing available." More likely, we will be saying, "Based on your history, you are at risk for a number of conditions for which there is now genetic testing."

We do not have the time or resources (or, for that matter, the desire) to see every patient eligible for each genetic test. Just like the alpha-fetoprotein blood test, which screens for neural tube defects and chromosome abnormalities during pregnancy, many genetic tests will be ordered by primary-care physicians and not geneticists. Rather than be threatened by this, we should seek out ways to implement our role as genetics experts and help primary-care physicians identify who should be offered a specific genetic test and which patients would benefit from a referral to a genetics clinic. The 1997 Johns Hopkins University study on genetic testing for familial adenomatous polyposis (FAP) found that almost one-third of the physicians misinterpreted the test results and close to $20 \%$ of the patients did not have a valid indication for testing (Giardiello et al., 1997). This study clearly 
demonstrates that our expertise is needed. The challenge will be to find effective ways to educate physicians about genetic counseling and testing so that patients are appropriately triaged and receive the care they need.

In the next few years, we can also anticipate more genetic testing with panels of genetic conditions, much like the one that already exists for Ashkenazi Jewish individuals. In what is known as the Ashkenazi Jewish screen, one blood sample can be tested for Tay-Sachs disease, Gaucher's disease, cystic fibrosis, and other conditions, regardless of the individual's family history and the variable age of onset of a condition like Gaucher's disease. As genetic testing becomes available for more genetic conditions, we will continually be faced with the challenges of presenting this information to our patients and determining the applicability of testing. It is important to keep in mind that just because testing is available does not obligate its use. With all of these genetic advances, it will no longer be possible to counsel patients effectively in a single clinic visit. As genetic counselors, we need to figure out what we want our role to be, what can be accomplished in a genetic counseling session, and what alternative options we should consider in educating patients about genetic conditions so that they can make informed decisions.

Nine years ago, I stood before the NSGC membership for the first time at a mike similar to this one in Cincinnati. I remember that my legs were shaking as I carefully worded the message that the time for our social event at the Brewery had been changed. I admit that my legs are still shaking today as I deliver my presidential address! The pathway to involvement is one that takes time, risks, networking, and shaky legs. As you embark down the road to involvement, there are counselors who will serve as mentors, colleagues who will become close friends. We welcome your participation, your ideas, and your feedback. The poet Ralph Waldo Emerson said, "Nothing great was ever achieved without enthusiasm." The NSGC Board of Directors has a lot of enthusiasm, and we look forward to a productive year.

\section{REFERENCES}

Bernhardt BA, Pyeritz RE (1989) The economics of clinical genetic services. III. Cognitive genetics services are not self-supporting. Am J Hum Genet 44:288-293.

Bernhardt BA, Weiner J, Foster EC, Tumpson JE, Pyeritz RE (1987) The economics of clinical genetic services. II. A time analysis of a medical genetics clinic. Am J Hum Genet 41:559-565.

Emerson RW (1841) Circles from Essays: First Series.

Giardiello FM, Brensinger JD, Petersen GM, Luce MC, Hylind LM, Bacon JA, Booker SV, Parker RD, Hamilton SR (1997) The use and interpretation of commercial APC gene testing for familial adenomatous polyposis. NEJM 336:823-827.

International Huntington Association and World Federation of Neurology Research Group on Huntington's Chorea (1994) Guidelines for the molecular genetics predictive test in Huntington's disease. Neurology 44:1533-1536.

National Society of Genetic Counselors (1992) Code of Ethics. J Genet Counsel 1(1):41-43.

Surh LC, Wright PG, Cappelli M, Kasaboski A, Hastings VA, Hunter AG, and the Molecular Genetic Study Group (1995) Delivery of molecular genetic services within a health care system: Time analysis of the clinical workload. Am J Hum Genet 56:760-768. 